\title{
El Leviatán de Hobbes. La destrucción del Estado, Cristo y el vientre del cocodrilo*
}

\author{
Johan TRALAU
}

Recibido:13 de abril de 2013.

Aceptado: 26 de agosto de 2013.

\section{RESUMEN}

En este artículo se aborda la cuestión de por qué Thomas Hobbes, consciente del poder político de las imágenes, tituló su opus magnum con el nombre del monstruo bíblico Leviathan (1651). El autor asegura que la imagen del Leviatán como el Estado alude a una interpretación contemporánea del monstruo como un cocodrilo. Más específicamente, se muestra cómo el cocodrilo fue interpretado como una imagen del diablo. Por otra parte, Hobbes, considerado por muchos un ateo o deísta, construye metáforas y símiles comparando la religión cristiana con algo que es tragado. Siendo conscientes de que el cocodrilo representa el Estado, Hobbes apunta esotéricamente sus desacuerdos con el cristianismo y su creencia de que la doctrina cristiana es destructiva para el Estado e inferior a los imperios paganos en su capacidad de inducir la obediencia de la ley por parte de los ciudadanos.

\section{PALABRAS CLAVE}

Thomas Hobbes, cocodrilo, alegoría, Leviatán, Cristianidad, religión pagana.

\begin{abstract}
This article addresses the question of why Thomas Hobbes named his 1651 philosophical magnum opus, Leviathan, after the Biblical monster. Depicting the state in this fashion alludes to a contemporaneous interpretation of Leviathan as a crocodile, an animal that could represent the Devil. Hobbes has been considered an atheist or deist who was acutely aware of the political power of images. Constructing metaphors and similes likening Christianity to something that is swallowed, and the state to a crocodile, Hobbes esoterically expressed his disagreement with the Christian religion. This illustrated his belief that the Christian doctrine was destructive to the state and inferior to pagan empires in its capacity to induce law-abiding behaviour among citizens.
\end{abstract}

* Este artículo fue publicado en sueco en: Johan Tralau, "Om statens undergång, Kristus och krokodilens mage Thomas Hobbes Leviathan i ljuset av en reptilallegori”: Svensk teologisk kvartalskrift, vol. 86 (2010), pp. 29-40. 


\section{KEYWORDS}

Thomas Hobbes, crocodile, allegory, Leviathan, Christianity, pagan religion.

Thomas Hobbes (1588-1679) es uno de los pensadores más importantes de la historia de la filosofía política. Bibliotecas enteras se han escrito sobre él y su opus magnum, Leviathan (1657). Pero, ¿por qué Hobbes - que censura ostentosamente el uso de imágenes literarias en prosa filosófica - titula su trabajo con el nombre de un monstruo marino bíblico y deja que el lector se halle frente a una metáfora monstruosa y enigmática? Expertos en Hobbes han debatido tradicionalmente sobre esta cuestión en relación con la hermenéutica bíblica o con fuentes clásicas. Lo que proponemos hacer aquí es algo que nunca se ha hecho antes: interpretar la imagen del monstruo de Hobbes en relación con un animal que fue considerado como un posible modelo para el Leviatán: el cocodrilo. Nosotros, en concreto, leeremos Leviathan con la ayuda de influyentes y antiguas concepciones sobre el cocodrilo, desde Aristóteles (384-322 a. e. c.) hasta llegar a una alegoría cristiana del mismo. Esta línea pretende ser una nueva forma de dar sentido a la desconcertante elección de Hobbes de titular a su obra Leviathan; así, veremos que la alusión al Leviatán como un cocodrilo puede ser entendida como una manera en la que Hobbes insertó una crítica clandestina del cristianismo. La interpretación, por lo tanto, arrojará una inesperada luz en la controvertida visión de este autor sobre el cristianismo, así como sobre las antiguas religiones paganas y el Estado moderno. El argumento se desarrollará de la siguiente manera: después de haber analizado estudios anteriores, nos desviaremos hacia nociones antiguas del cocodrilo y de un animal que es tragado por el cocodrilo pero que aún así mata al gran depredador desde su interior. Posteriormente, trataremos la comprensión alegórica cristiana de esta historia como Cristo derrotando a Satán. En un segundo paso, exploraremos las metáforas de la ingestión en Leviathan, que dejarán claro cómo Hobbes utiliza imágenes de animales en los intestinos como fuerzas parasitarias y destructivas. Finalmente, argumentaremos que la imagen del Leviatán como un cocodrilo es además un arcano, es decir, una manera alegórica de Hobbes para sugerir que el cristianismo es una fuerza subversiva para la figura del Estado y la autoridad política ${ }^{1}$.

${ }^{1}$ El autor quisiera agradecer a Katarina Barrling Hermansson, Sara Danius, Gina Gustavsson, Jörgen Hermansson, Magnus Kristiansson, Oscar Larsson y Jörgen Ödalen. El texto forma parte del proyecto: "Thomas Hobbes's Last Secret. Mythology, Politics, and the Enigmatic Mon-ster Leviathan”, financiado por el Consejo de Investigación Sueco. 


\section{EL REDESCUBRIMIENTO DE LAS IMÁGENES DE HobBES}

Hobbes es famoso por su feroz crítica a la falta de claridad conceptual. De hecho, sostenía que toda la filosofía política anterior era confusa y equívoca debido a su uso ambiguo, absurdo y metafórico del lenguaje. Según una anécdota del propio autor, una vez se encontró con la obra Los Elementos de Euclides (ca. 325-265 a. e. c.) en una biblioteca y la leyó al revés, iniciando por las conclusiones y terminando por los principios y llegó a la idea de que la filosofía política debería funcionar de la misma manera, es decir, a través de la transparencia, de la deducción cristalina de los principios bien definidos ${ }^{2}$. La propia teoría política de Hobbes se inicia con un principio radical y moderno, a saber, que "nadie está obligado por un Pacto, del cual él no sea el autor"3. De este principio, intenta deducir una obligación casi absoluta de obedecer a la ley - de acuerdo con su teoría, los ciudadanos han autorizado previamente todos los futuros actos del soberano: "Todo hombre particular es autor de todo cuanto el soberano hace" - . No podemos hacer caso omiso de las llamadas de Hobbes a la claridad y al rigor conceptual. De hecho, hasta hace poco Hobbes ha sido visto como el gran geómetra de la filosofía política ${ }^{5}$. No obstante, siempre ha habido una buena razón para sospechar que Hobbes no pretende ser tan transparente como dice serlo: durante su vida, ser "hobbessiano" se convirtió en un sinónimo de "ateo", una acusación que él mismo negaba. Un pequeño número de expertos sobre Hobbes sostienen que era un protestante inusual pero sincero. Otros afirman que Hobbes era un ateo o deísta, una visión que él transmitía a ciertos lectores principiantes o meticulosos

${ }^{2}$ Thomas HobBes, "T. Hobbes malmesburiensis vita", en Opera philosophica quce latine scripsit omnia in unum corpus nunc primum collecta, ed. de William Molesworth, I, Bohn, London, 1845, pp. xiii-xxi, esp. p. xiv.

3 "[N]o man is obliged by a Covenant, whereof he is not Author". Thomas HobBES, Leviathan, ed. de G. A. J. Rogers y Karl Schuhmann, II, Continuum, London, 2005, xvi, 6, p. 129 (los números romanos indican capítulo, los números que preceden a los números de página se refieren al sistema de párrafos en la edición de Edwin Curley: Leviathan, Hacket, Indianapolis, 1994). En castellano: Thomas HobBes, Leviatán, ed. de Carlos Moya y Antonio Escohotado, Editorial Nacional, Madrid, 1980, p. 256.

${ }^{4}$ HobBes, Leviathan, xviii, 6, p. 141, cf. 140ss.: "Every Subject is by this Institution Author of all the Actions, and Judgments of the Soveraigne Instituted; it followes, that whatsoever he doth, it can be no injury to any of his Subjects; nor ought he to be by any of them accused of Injustice". [Todo hombre es por su institución autor de todas las acciones y juicios del soberano; se entiende que cualquier acción que haga no puede herir a ninguno de sus súbditos. Ni puede ser acusado de injusticia por alguno de ellos.]

${ }^{5}$ Jean HAMPTON, Hobbes and the Social Contract Tradition, Cambridge University Press, Cambridge, 1986, p. 1. 
mediante signos esotéricos ${ }^{6}$. Este es un debate importante, y más adelante tendremos razón para volver a ello y descubrir un nuevo e importante argumento.

Los últimos años han sido testigos de una revolución en los estudios sobre Hobbes: cada vez más se ha prestado una atención especial al uso de metáforas y otras imágenes por parte de este autor. El historiador de arte Horst Bredekamp ha mostrado la importancia que las imágenes tienen en la doctrina psicológica y epistemológica de Hobbes. Sobre la base de las portadas de los libros de su obra (en la producción de las cuales podemos afirmar que Hobbes estuvo intensamente involucrado), Bredekamp reconstruye un proyecto misterioso, cuyo objetivo es persuadir al lector por medio de imágenes en lugar de argumentos y silogismos $^{7}$. De forma similar, otros académicos han argumentado que Hobbes debe ser redescubierto como un retórico y creador de imágenes ${ }^{8}$.

En este punto, debemos destacar que el giro hacia las imágenes en los estudios de Hobbes no es una transgresión anacrónica o estetizante en el territorio puro de la filosofía política. Es Hobbes mismo quien atribuye efectos extraordinarios a las imágenes - efectos sobre el pensamiento y las acciones de las personas-. Este no es el lugar para reconstruir la teoría mecanicista de Hobbes sobre la cognición; es suficiente señalar que según este autor, todos los pensamientos se originan en la percepción, como resultado de la presión física en el

${ }^{6}$ Para la primera interpretación, cf. A. P. Martinich, "The Bible and Protestantism in Leviathan", en Patricia Springborg (ed.), Cambridge Companion to Hobbes's Leviathan, Cambridge University Press, Cambridge, 2007, pp. 375-391; para la segunda interpretación, Edwin Curley, "Calvin and Hobbes, or, Hobbes as an orthodox Christian": Journal of the History of Philosophy, vol. XXXIV, n. ${ }^{\circ} 2$ (April 1996), pp. 257-271. La respuesta de MARTINICH, "On the Proper Interpretation of Hobbes's Philosophy”, en el mismo número, pp. 273-283; cf. también David Berman, "Disclaimers as offence mechanisms in Charles Blount and John Toland", en Michael Hunter and David WootTon (eds.), Atheism from the Reformation to the Enlightenment, Oxford University Press, Oxford, 1992, pp. 255-272, y Patricia SpRINGBORG, "Hobbes and Epicurean religion", en Gianni Paganini y Edoardo TorTarolo (eds.), Der Garten und die Moderne: Epikureische Moral und Politik vom Humanismus bis zur Aufklärung, Frommann-Holzboog, Stuttgart \& Bad Cannstatt, 2004, pp. 161-214.

${ }^{7}$ Horst BredeKAMP, Thomas Hobbes Der Leviathan. Das Urbild des modernen Staates und seine Gegenbilder 1651-2001, Akademie, Berlin, 2006, pp. 18, 71ss., 131.

${ }^{8}$ Quentin SkINNER, "Hobbes's Changing Conception of Civil Science", en Visions of Politics, III, Hobbes and Civil Science, Cambridge University Press, Cambridge, 2002, pp. 66-86; SkInNER, Reason and Rhetoric in the Philosophy of Hobbes, Cambridge University Press, Cambridge, 1996, passim; Raia ProKHOVNIK, Rhetoric and Philosophy in Hobbes' Leviathan, Garland, London \& New York, 1991, passim; David Johnston, The Rhetoric of Leviathan. Thomas Hobbes and the Politics of Cultural Transformation, Princeton University Press, Princeton, 1986, passim. 
ojo o en algún otro órgano perceptor ${ }^{9}$. Lo que significa que las imágenes adquieren una enorme importancia política. Son, de hecho, los medios más eficaces para el control de los ciudadanos y para inducirlos a que cumplan con la ley ${ }^{10}$. Por supuesto, Hobbes no dice explícitamente que las imágenes se deban utilizar con el fin de lograr el Estado previsto en Leviathan. De acuerdo con su doctrina oficial, las imágenes - en particular las metáforas - son manipuladoras; los ciudadanos y los lectores no deben ser engañados por metáforas tales como las empleadas por los eruditos católicos con el propósito de adquirir poder sobre las mentes de las personas ${ }^{11}$. Curiosamente, su postura es más neutral o encubiertamente positiva cuando habla de la utilización de imágenes políticas en las sociedades paganas antiguas, "DEMONOLOGIA" que sirvió "para la paz pública y la necesaria obediencia de los súbditos al efecto", y que, además, utilizó "fantasmas", "para hacer algunos de los daimones buenos y otros malos; unos para espolear la obediencia y otros como frenos para disuadir de una violencia de las leyes"12. Estos pasajes muestran que, según la doctrina de Hobbes, las imágenes -físicas, literarias o mentales - son exuberantes y poderosos instrumentos políticos. El propio uso de las metáforas e imágenes en las portadas de sus obras debería alertarnos sobre la posibilidad de que las imágenes que utiliza tengan propósitos políticos muy concretos.

Una cuestión fundamental en este contexto es saber por qué Hobbes — quien oficialmente censura imágenes literarias y defiende la ciencia moderna - titula su gran obra, Leviathan, con el nombre de un monstruo marino. Carl Schmitt (18881985) fue posiblemente el primer autor que realmente se dio cuenta de la importancia de este tema. En su pequeño y críptico libro de 1938 sobre Leviathan, Schmitt señala que Hobbes solo menciona el nombre tres veces en su libro. Además, lo hace de muy diversas maneras: como una máquina, un hombre y un

${ }^{9}$ HobBes, Leviathan, i, 2, p. 13: "There is no conception in a mans mind, which hath not at first, totally, or by parts, been begotten upon the organs of Sense". [No hay concepción en la mente del hombre, que no haya sido primero capturada en parte o su totalidad por los órganos del Sentido]. Cf. Cees Leijenhorst, "Sense and Nonsense About Sense: Hobbes and the Aristotelians on Sense Perception and Imagination", en Patricia Springborg (ed.), Cambridge Companion to Hobbes's Leviathan, Cambridge University Press, Cambridge, 2007, pp. 82-108.

${ }^{10}$ Johan Tralau, "Deception, Politics and Aesthetics: The Importance of Hobbes's Concept of Metaphor", en Contemporary Political Theory, en prensa (2013); Patricia SpRINGBorG, "Hobbes and historiography: Why the future, he says, does not exist", en G. A. J. ROGERS y Tom SORRELL (ed.), Hobbes and History, Routledge, London, 2000, pp. 44-72, en p. 58.

${ }^{11}$ Hobbes, Leviathan, xxix, 15, p. 259, cf. xxv, 12, p. 206, donde Hobbes dice que las metáforas son "usefull onely to deceive" [útiles principalmente para engañar].

${ }^{12}$ Ibid., xlv, 2, p. 508. 
dios ${ }^{13}$. El monstruo bíblico se convierte así en tres cosas diferentes ${ }^{14}$. El Leviatán no es por lo tanto una metáfora, sino toda una "familia de metáforas" 15 . Schmitt no es capaz de dar sentido a este raro enigma, aunque extrañamente asegura que es "un gesto semi-irónico, literario, nacido del buen humor inglés"16.

Ahora podemos encontrar explicaciones de los elementos individuales en el conglomerado de imágenes de Hobbes. El componente mecánico es, así, una ilustración de su metafísica materialista, según la cual la realidad es material y todo cambio es debido al movimiento físico - de esta manera el mundo se asemeja o, más precisamente, es una máquina ${ }^{17}$ —. Del mismo modo, la imagen del Leviatán como un hombre representa una premisa hobbesiana fundamental, a saber, que el Estado se convierte en una persona en el soberano, ya que los ciudadanos han autorizado las acciones futuras del mismo ${ }^{18}$.

Pero, ¿por qué el Leviatán, por qué un monstruo bíblico? ${ }^{19}$. Una respuesta preliminar es la ofrecida en un pasaje del libro de Job, que se encuentra en la portada y en la obra: Non est potestas super terram quae comparetur e $i^{20}$. Hobbes sostiene que su fuerza es incomparable con la de los demás —el texto de la Vulgata enfatiza potestas, lo que es decisivo para el origen de las comunidades políticas-, pues sólo el Estado puede adquirir un poder inigualable y poner fin a la guerra de todos contra todos ${ }^{21}$. Otra respuesta es que el título es una provocación

${ }^{13}$ Carl Schmitt, Der Leviathan in der Staatslehre des Thomas Hobbes. Sinn und Fehlschlag eines politischen Symbols, Klett-Cotta, Stuttgart, 1995, pp. 29ss.

${ }^{14}$ HobBes, Leviathan, Introduction, 1, p. 9; xvii, 13, p. 137; xxviii, 27, p. 252.

${ }^{15}$ Gianluca Briguglia, Il corpo vivente dello stato. Una metafora politica, Mondadori, Milano, 2006, p. 124.

16 "[E]in aus gutem englischen Humor geborener, halbironischer, literarischer Einfall". Schmitt, Der Leviathan, p. 31, n. 1. Traducción española: El Leviatán en la teoría del Estado de Tomás Hobbes, trad. de Javier Conde, Struhart \& Cía., Buenos Aires, 2002, p. 18, nota 2.

${ }^{17}$ Schmitt, Der Leviathan, p. 61; BredeKamp, Thomas Hobbes Der Leviathan, p. 59; Noel Malcolm, "Hobbes's Science of Politics and His Theory of Science", en Aspects of Hobbes, Oxford University Press, Oxford, 2002, pp. 146-155, esp. pp. 150ss.

${ }^{18}$ Malcolm, "Hobbes's Science of Politics and His Theory of Science", pp. 150ss.

${ }^{19}$ Intentos vagos de interpretar la metáfora del Leviatán incluyen Charles TARLTON, "Levitating Leviathan: Glosses on a Theme in Hobbes": Ethics, vol. LXXXVIII, n. ${ }^{\circ} 1$ (1977), pp. 1-19; George Shulman, "Metaphor and Modernization in the Political Thought of Thomas Hobbes": Political Theory, vol. XVII, n. ${ }^{\circ} 3$ (1989), pp. 392-416.

${ }^{20}$ Job 41:24. Citado (en inglés) en HobBes, Leviathan, xxviii, 27, p. 252.

${ }^{21}$ Ross Harrison, Hobbes, Locke, and Confusion's Masterpiece, Cambridge University Press, Cambridge, 2003, pp. 44ss.; HoBbes, Leviathan, xiii, 1, p. 99. Cf. Leo Strauss, Hobbes' politische Wissenschaft in ihrer Genesis, en Gesammelte Schriften, ed. de Heinrich y Wiebke 
deliberada; Hobbes es consciente del hecho de que, en la tradición cristiana, el Leviatán está asociado con Satán ${ }^{22}$.

Aún así, hay algo insatisfactorio en esta respuesta. ¿Por qué esta imagen enigmática? ¿Por qué un monstruo? ¿Por qué el Leviatán? Durante mucho tiempo, los académicos no han logrado dar una respuesta adecuada ${ }^{23}$. En otro lugar hemos sostenido que la imagen del Leviatán debe entenderse precisamente como algo que es radicalmente contradictorio e indeterminado, y que el monstruo debe leerse a la luz de otros monstruos indeterminados del universo mítico que Hobbes conocía bien ${ }^{24}$. Según esta lectura, el monstruo es, pues, un tropo mítico y literario que representa un componente fundamental en la construcción teórica de Hobbes, principalmente la idea de que el soberano no está sujeto a las normas que se aplican a los ciudadanos. Noel Malcolm ha sugerido que la elección del nombre refleja la influencia del erudito hebreo Jacques Boulduc, quien argumentó que "Leviatán" deriva de una palabra hebrea que significa "unión". En su exilio parisino, Hobbes puede haber llegado a esta visión a través de su amigo Marin Mersenne (1588-1648) y apropiársela para su propio proyecto; después de todo, el propósito del Estado de Hobbes es que el soberano incorpore a los ciudadanos y los convierta en una unidad ${ }^{25}$. La propuesta de Malcolm es importante, pero todavía nos podríamos preguntar por qué Hobbes centraría tanto la atención de su gran obra en un punto bastante evidente y no controvertido ${ }^{26}$. El objetivo de lo que sigue no es tratar de refutar esta interpretación, sino sugerir un camino diferente. Hobbes convierte al monstruo en un hombre, en una máquina y en un dios. De este modo le permite al monstruo ser todo menos un animal. Sin embargo, lo que Hobbes no dice puede ser tan importante como lo que sí dice.

MeIER, III, Hobbes 'politische Wissenschaft und zugehörige Schriften-Briefe, Metzler, Stuttgart \& Weimar, 2001, pp. 3-192, esp. p. 26, cf. p. 133.

${ }^{22}$ Pero no exclusivamente con Satán; ver Tomaž MastnaK, "Schmitt’s Behemoth", en Johan Tralau (ed.), Thomas Hobbes and Carl Schmitt. The Politics of Order and Myth, Routledge, London, 2011, pp. 17-39.

${ }^{23}$ Wolfgang Kersting, Thomas Hobbes zur Einführung, Junius, Hamburg, 2002, pp. 41ss.; Herfried Münkler, Thomas Hobbes, Campus, Frankfurt/Main \& New York, 2001, p. 44.

${ }^{24}$ Johan Tralau, "Leviathan, the Beast of Myth. Medusa, Dionysos, and the Riddle of Hobbes's Sovereign Monster", en Patricia SpringBorg (ed.), Cambridge Companion to Hobbes's Leviathan, Cambridge University Press, Cambridge, 2007, pp. 61-81.

${ }^{25}$ Noel Malcolm, "The Name and Nature of Leviathan: Political Symbolism and Biblical Exegesis": Intellectual History Review, vol. XVII, n. ${ }^{\circ} 1$ (2007), esp. p. 27.

${ }^{26}$ Patricia Springborg argumenta, sin embargo, que la interpretación de Malcolm debe ser vista a la luz de la concepción de la representación, y que esto la haría más controvertida. Véase: 
Nosotros sugeriremos que una cierta concepción zoológica y alegórica del Leviatán inherente a la tradición y a la propia época de Hobbes - una noción que el autor no tuvo que declarar explícitamente- es la clave para entender la imagen. La elección de las imágenes debe relacionarse con el imaginario en el que sus lectores habitaban. Entonces, la pregunta es, qué tema hermenéutico resuena en la composición del Leviatán, que es asumido en la imagen, pero que no está declarado por Hobbes. Más concretamente, ¿por qué Hobbes usa "un animal marino, cocodrilo, ballena o pez grande" (en palabras de Schmitt) como una imagen del monstruo estatal que luego se describirá como algo completamente diferente? ${ }^{27}$. Vamos a sugerir una posible explicación — centrada en una determinada criatura acuática: el cocodrilo- - Veremos que una interpretación basada en el cocodrilo revelará posibilidades inesperadas, pues en la primera parte del siglo diecisiete, había algo especial en interpretar el Leviatán como un cocodrilo.

\section{CRISTO, EL COCODRILO Y EL ENEMIGO DEL REPTIL: DESDE LA HiSTORIA ANIMA- lium de Aristóteles al Physiologus}

Hobbes elige al Leviatán como la imagen de su Estado. El Leviatán puede ser un cocodrilo. Por tanto, debemos preguntarnos qué concepciones del cocodrilo han sido puestas en marcha. Si Hobbes, de hecho, opera con imágenes como medio para influir en los pensamientos de una manera en la que debemos suponer que estas apoyan y complementan la argumentación racional, podemos entonces sospechar que incorpora imágenes influyentes de las tradiciones que él desprecia. Su rechazo brutal de la antigua tradición y su filosofía es bien conocido ${ }^{28}$. En particular, Hobbes reprueba a Aristóteles. Esto no debería resultar una sorpresa dada la visión de Hobbes sobre la influencia del aristotelismo en las universidades

Patricia Springborg, "Hobbes and Schmitt on the Name and Nature of Leviathan Revisited", en Johan Tralau (ed.), Thomas Hobbes and Carl Schmitt. The Politics of Order and Myth, Routledge, London, 2011, pp. 39-57; también en Critical Review of International Social and Political Philosophy, vol. XIII, n. ${ }^{\circ}$ 2-3 (2010), pp. 297-315.

27 "[E]in großes wassertier del als Krokodil, Walfisch, oder allgemein del als ein großer Fisch". SснмітT, Der Leviathan, p. 11. Traducción española: El Leviatán en la teoría del Estado de Tomás Hobbes, p. 7.

${ }^{28}$ Reinhart Koselleck lo describe bien cuando dice: "Das Licht der Vernunft verleiht Hobbes auch ein strenges Überlegenheitsbewußtsein über die ganze Vergangenheit, über ihre Unwissenheit und ihren Aberglauben". [La luz de la razón confiere a Hobbes una severa conciencia de superioridad sobre todo el pasado, su ignorancia y su superstición]. Reinhart KosELLECK, Kritik und Krise. Eine Studie zur Pathogenese der bürgerlichen Welt, Suhrkamp, Frankfurt/Main, 1973, p. 166, n. 72. 
europeas de su época. Sin embargo, curiosamente, según las Vidas Breves de John Aubrey (1626-1697), Hobbes hizo dos excepciones: este autor subrayó que Hobbes apreciaba la Retórica de Aristóteles, así como la obra del filósofo sobre los anima$\operatorname{les}^{29}$. Es interesante cómo Leo Strauss (1899-1973) ha demostrado que el filósofo de Malmesbury incorpora largos pasajes de la Retórica de Aristóteles en sus obras publicadas, a menudo traducciones literales. Sin embargo, Strauss añadió que los libros sobre los animales de Aristóteles no parecen haber influido en Hobbes ${ }^{30}$. Pero quizás Strauss estaba equivocado. Por supuesto, no encontramos un Leviatán ugarítico, judío o cristiano en Aristóteles. Pero sí encontramos al cocodrilo.

Aristóteles nos dice que los cocodrilos tienen sus dientes cepillados por los trochilos, una especie de aves a las que el cocodrilo permite comer los restos de comida que están atrapados entre los dientes del gran animal (Historia Animalium 612a21-24). No vamos a lidiar con este pájaro imaginario en esta coyuntura. Pero la afirmación sobre el pájaro va precedida de otra interesante "observación", una visión que disfrutaría de una vida futura fascinante. Aristóteles habla de otro animal, ichneumōn o mangosta egipcia, un roedor que se revuelca en el barro con el fin de proteger su cuerpo antes de atacar a las serpientes, más específicamente "la serpiente llamada aspis (áspid)" (ton ophin tèn aspida kaloumenēn, Historia Animalium 612a16-21). Posteriormente, en la Antigüedad, el animalito valiente adquiriría un papel aún más extraordinario, ya que varios autores influyentes afirmarán que el ichneumōn era el archienemigo del cocodrilo. El historiador Diodoro de Sicilia (90-30 a. e. c.) transmite un dato curioso: el ichneumōn mata cocodrilos de una "forma sorprendente y ciertamente increíble" (paradoxōs kai pantelōs apistoumenēi methodōi, Diodoro I.87.5). Cuando el cocodrilo duerme, mantiene la boca abierta. Después de tomar las precauciones necesarias de cubrir su cuerpo con barro, el ichneumōn salta a la boca del cocodrilo, se deja devorar, y mata al gran animal desde dentro al morder a través de sus intestinos y vientre; luego, se arrastra fuera del agujero. Gayo Plinio Segundo (23-79 e. c.), en su historia natural, relata la misma historia ${ }^{31}$. De hecho, esta se convirtió en la versión estándar del pequeño ichneumōn en la Antigüedad pagana tardía, y dio un giro notable en la literatura cristiana ${ }^{32}$.

${ }^{29}$ AuBrey, Brief Lives, ed. Clark, I, p. 357: “[B]ut his [Aristotle's] rhetorique and discourse of animals was rare". [Pero su [de Aristóteles] retórica y discurso sobre los animales era raro]. Citado en STRauss, Hobbes 'politische Wissenschaft, p. 50.

${ }^{30}$ Strauss, Hobbes' politische Wissenschaft, pp. 45-59, 97, 152ss.

${ }^{31}$ Gayo Plinio Segundo, Naturalis historia, VII.xxxvii.90.

${ }^{32}$ Ver John BERNSTRÖM "Krokodil och ichneumon, trochilus och flodhäst”, en Bernströms bestiarium. En djurens nordiska kulturhistoria, ed. de Henrik Otterberg, Atlantis, Stockholm, 2008, pp. 202-207, esp. p. 205. 
En un libro sobre animales, influyente en la Europa premoderna, el ichneumōn y el cocodrilo se convirtieron en un tema cristiano crucial. La obra, llamada Physiologus, fue escrita por un autor anónimo, probablemente en Alejandría hacia la mitad del siglo dos, y circuló en un gran número de versiones en varios idiomas, incluyendo el inglés. Contiene interpretaciones alegóricas de animales, siguiendo una perspectiva cristiana, con algunos animales representando las virtudes cristianas y otros sus vicios correspondientes. Mitos paganos, como el de Fénix, fueron reinterpretados según la nueva fe. Así, el Fénix se entendió como una imagen de Cristo, debido a la supuestamente voluntaria muerte y resurrección del $a^{3} e^{33}$. En una línea similar, el pequeño asesino de cocodrilos fue interpretado como un símbolo de Cristo venciendo la muerte:

[El animal] embadurna su cuerpo entero con barro...se lanza dentro de la boca del cocodrilo, muerde a través de todo el paso y se come los intestinos. Así el cocodrilo se asemeja al diablo, y el enydros representa nuestro Salvador, puesto que después de que nuestro Señor hubiese tomado un aspecto terrenal, descendió al reino de los muertos y liberó [la humanidad] de los tormentos de la muerte ${ }^{34}$.

Hay una cierta confusión sobre las diferentes especies. Mientras Aristóteles dice que el ichneumōn es enemigo de la serpiente (en este caso aspis); Diodoro, Plinio y otros autores paganos de la Antigüedad tardía afirman que el ichneumōn es un asesino de cocodrilos. En el libro cristiano de los animales por excelencia, el Physiologus, una nueva transformación ha ocurrido: el autor habla del pequeño animal como el enemigo de la serpiente (en este caso drakōn; por supuesto, alegóricamente también el enemigo del Diablo) y, curiosamente, como un animal parecido al cerdo ${ }^{35}$. Sin embargo, en el pasaje anterior se menciona un animal llamado enydros, "que se parece a un perro" (morfên echousa kynos) $)^{36}$ y ha asumido el papel bien conocido del asesino de cocodrilos. En otras versiones europeas, el nombre ichneumōn se mantuvo para el animal que representa a Cristo. Proba-

${ }^{33}$ Ver "Fenix", en Bernströms bestiarium, pp. 96-97.

34 "chrietai holon to sōma pēlōi...halletai eis to stoma tou krokodeilou kai pantas tous porous autou trōgei kai ta egkata katesthiei. eoiken oun ho krokodeilos tōi diabolōi, hē de enydros eis to tou Sōtēros hēmōn prosōpon lambanetai· labōn gar ho Kyrios hēmōn tēn choikēn sarka katebē eis ton Haidēn kai elyse tas odynas tou thanatou". Physiologus, cap. 25; seguimos el texto en la edición de Otto Schönberger, Physiologus, Reclam, Stuttgart, 2005, p. 42. El texto ha variado en el transcurso de la historia, aunque para nuestro propósito, podemos asumir que su significado ha permanecido siendo más o menos el mismo.

${ }^{35}$ Physiologus, 26, p. 42.

${ }^{36}$ Ibid., 25, p. 42. 
blemente no hay que preocuparse demasiado por el cambio de nombres ${ }^{37}$. En su papel, este animal corresponde al ichneumōn. La criatura se revuelca en el barro, en el texto griego chrietai, "se unge", lo que se relaciona con el ungido, Christos; y el barro se convierte en una especie de armadura o protección. Corre a través de la faringe del cocodrilo y luego muerde hasta la muerte desde el interior. Merece especial atención señalar que el asesino de cocodrilos adquiere un significado alegórico: Cristo es quien se lanza voluntariamente por el barranco de la muerte y la derrota. A la inversa, el cocodrilo es el Diablo, al que el enydros permite que lo devore con el fin de derrotar al reptil diabólico desde dentro. A pesar de los confusos nombres y especies, el simbolismo es claro: Cristo se lanza a la carne y vence a la muerte desde el interior ${ }^{38}$.

El ichneumōn es, así, en Aristóteles, el enemigo de la serpiente, posteriormente, el enemigo de los cocodrilos, y por último - aunque en algunas versiones con un nombre diferente- es una representación alegórica de Jesús, al igual que el cocodrilo es el diablo y el mundo vencido por Cristo.

Pero ¿por qué molestarnos? Hobbes concibe, como hemos dicho, su Estado como un monstruo que a su vez se puede interpretar como un cocodrilo. Y si la idea del cocodrilo es de alguna manera significativa, entonces debemos buscar su posible significado en el mundo de las imágenes aún utilizadas en la época de Hobbes. Permítannos esbozar una conclusión preliminar: debido a su extraordinaria selección de imágenes, Hobbes parece hacer ver a sus lectores y espectadores que el Estado hobbesiano es, precisamente, el monstruo derrotado por Cristo. Cristo es el enemigo del Leviatán. Cristo puede vencer al monstruo estatal de Hobbes, rajando su vientre desde dentro.

${ }^{37}$ John Bernström sugiere que el cambio de nombre pudo haber tomado lugar debido a que las personas conocedoras de la mangosta, no la creían suficientemente digna para representar al salvador. BERNSTRÖM, "Krokodil och ichneumon", p. 205. En las otras partes del texto, ichneumōn asume el rol de Cristo (elabe tèn tou choos genous ousian, 26).

${ }^{38}$ Metáforas y alegorías similares sobre la pesca pueden ser encontradas en muchos otros lugares dentro de la tradición cristiana, particularmente respecto con la cruz como el garfio por el cual el diablo es atrapado. Schmitt cita una canción cantada por peregrinos en la Edad Media: "O crux benedicta, / aller holze beszista,/ an dir wart gevangan / der gir Leviathan". ScHMITT, Der Leviathan, p. 16. Existe, por supuesto, la imagen de la salvación como pescar: Mateo 4:19: "Yo os haré pescadores de hombres" (poiēsō hymas halieis anthrōpōn). 


\section{LAS METÁFORAS DE LA INGESTIÓN}

El propósito de este artículo no es entretenerme en fantasmas hermenéuticos. Si la interpretación es demasiado inverosímil no hay ningún objetivo en su búsqueda. Sin embargo, hemos visto que la elección de imágenes de Hobbes parece establecer una conexión entre el Estado, por un lado, y el animal trascendido por Cristo, por el otro. Cristo es devorado por el cocodrilo y lo derrota. Tal vez la imagen sugiere que el cristianismo es destructivo y hostil al Estado, tan vigorosamente defendido por Hobbes. Para apoyar esta interpretación, tenemos que encontrar una prueba más circunstancial, necesitamos algunas indicaciones en el texto de Hobbes en las que el Cristo devorado pudiera ser sospechoso de la destrucción del Estado. Inglaterra pronto llegaría a ver un proyecto de ley que implicaba que la negación de la inmortalidad del alma (como, no por casualidad, Hobbes hizo) se castigase con la cárcel o el exilio ${ }^{39}$. En este contexto, Hobbes no podía cuestionar explícitamente el valor político o la viabilidad de la cristiandad. Una forma de hacerlo sería a través de un sustituto, por ejemplo, mediante una metáfora.

La cuestión es, entonces, si Hobbes emplea otras metáforas sobre la ingestión y sobre animales en el estómago; metáforas que, indirectamente, transmitan o apoyen la idea de que la lucha del animal-Cristo contra el cocodrilo fuese relevante en este contexto.

Hobbes es famoso por su crítica del pluralismo político y social ${ }^{40}$. Las organizaciones y comunidades que exigen lealtad a los ciudadanos son particularmente problemáticas para Hobbes. En un momento importante en el texto, se utiliza una metáfora sorprendente:

Otra enfermedad de una república es el volumen inmoderado de una ciudad, cuando es capaz de proveer dentro de su propio circuito el número y los gastos de un gran ejército. Como también el gran número de corporaciones, que son como muchas pequeñas repúblicas en los intestinos de una mayor, semejantes a las lombrices en las entrañas de un hombre natural. A lo cual puede añadirse la libertad para disputar contra el poder soberano en quienes pretenden poseer prudencia política; cosa que, aunque criada en su mayoría en las heces del pueblo pero animada

${ }^{39}$ Ver Richard Tuck, "Hobbes and Locke on Toleration", en Mary Dietz (ed.), Thomas Hobbes and Political Theory, University Press of Kansas, Lawrence, Kansas, 1990, pp. 153-171, en pp. $157 \mathrm{ss}$.

${ }^{40}$ Richard Boyd, "Thomas Hobbes and the Perils of Pluralism": Journal of Politics, vol. LXIII, n. ${ }^{\circ} 2$ (2001), pp. 392-413. 
por falsas doctrinas, entorpece perpetuamente las leyes fundamentales para trastorno de la república, como los pequeños gusanos que los médicos llaman ascárides ${ }^{41}$.

La comparación del Estado con un gran cuerpo no es una innovación, se trata de un locus communis en el pensamiento político occidental. En Tito Livio (59 a. e. c.-17 e. c.), a quien volveremos pronto, nos encontramos con la imagen del Estado como un organismo en el que los miembros, el vientre y la cabeza tienen que trabajar para el mismo propósito. La metáfora del cuerpo estatal está virtualmente omnipresente, y experimenta extraños cambios a lo largo de la historia $^{42}$. Hay una buena razón para explorar las imágenes de Hobbes del Estado como cuerpo de una manera nueva y diferente de la de las investigaciones precedentes. Es, por ejemplo, notable que ni Gianluca Briguglia (en un libro acerca de la metáfora del cuerpo estatal) ni Quentin Skinner (quien discute brevemente esta misma metáfora) llamen la atención sobre el hecho de que las imágenes sobre el Estado-cuerpo en Leviathan son demasiado monstruosas, a veces incluso grotescas ${ }^{43}$. Cuando Hobbes habla de la separación de poderes, como en los casos en que la fiscalidad y los poderes ejecutivo y legislativo no están en las mismas manos, él compara esta supuesta aberración con una malformación, una condición en la que unos cuerpos adicionales crecen a los lados exteriores del cuerpo humano, una especie de trillizos siameses ${ }^{44}$. En cualquier caso, la imagen de Hobbes de las asociaciones dentro de los Estados trasciende las concepciones tradicionales. Lo que hace que su imagen sea tan novedosa es el hecho de que estas asociaciones son comparadas con gusanos en los intestinos del cuerpo estatal. El símil es muy específico: los gusanos parasitando el cuerpo son ascárides, una especie de gusano mencionada en la obra zoológica de Aristóteles. O, más específicamente, dos especies, aunque sea fácil confundirlas entre sí. Aristóteles escribe que los askarides son gusanos que viven en arcilla putrefacta (Historia Animalium 551b28). En el caso de Hobbes, sin embargo, puede ser que se trate

41 "Another infirmity of a Common-wealth, is the immoderate greatnesse of a Town, when it is able to furnish out of its own Circuit, the number, and expence of a great Army: As also the great number of Corporations; which are as it were many lesser Common-wealths in the bowels of a greater, like wormes in the entrayles of a naturall man. To which may be added, the Liberty of Disputing against absolute Power, by pretenders to Politicall Prudence, which though bred for the most part in the Lees of the people; yet animated by False Doctrines, are perpetually medling with the Fundamentall Lawes, to the molestation of the Common-wealth; like the little Wormes, which Physicians call Ascarides". HobBEs, Leviathan, xxix, 21, p. 263. HobBes, Leviatán, pp. 405-406.

${ }^{42}$ BRIGUGLIA, Il corpo vivente dello stato, passim.

${ }^{43}$ Ibid., pp. 142ss. SKInNER, Reason and Rhetoric in the Philosophy of Hobbes, pp. 387ss.

${ }^{44}$ HobBes, Leviathan, xxix, 17, p. 261. 
de otro tipo de gusano al que Aristóteles etiqueta como akarides (pero no podemos estar absolutamente seguros, porque también existe la variante askarides). En una discusión sobre animales que no han nacido de los individuos de su especie, sino (se pensaba) espontáneamente de otros tipos de materia (ta d'ouk ek zōiōn all'automata, 551a1), Aristóteles habla precisamente de estos gusanos que viven en los cuerpos de los animales o seres humanos (en tois zöiois, 551a8). Los gusanos se originarían de forma espontánea en el cuerpo del animal anfitrión y vivirían fuera de él. Probablemente no deberíamos exagerar la importancia del hecho de que Aristóteles mencione a estos animales en uno de los dos libros que Hobbes se supone que había apreciado —o de hecho, que Hobbes use la palabra automaton del cuerpo humano en la introducción a Leviathan ${ }^{45}$ - . El símil de Hobbes es audaz: como veremos, los gusanos parasitando el organismo estatal es una imagen original en la historia del pensamiento político ${ }^{46}$.

En un texto a menudo olvidado sobre la poética, Hobbes escribe que una metáfora de éxito debe navegar entre dos extremos destructivos. Por un lado, la metáfora no debe ser sencilla ni partir del lenguaje corriente y, por otro lado, no debe ser demasiado extraña, demasiado manierista. Así pues, la metáfora debe ser ligeramente inverosímili ${ }^{47}$. Hobbes se apropia y revisa la concepción de las buenas metáforas de Aristóteles, según la cual una metáfora no debe ser invero-

${ }^{45}$ Ibid., "Introduction", 1, p. 9.

46 "Sería más improbable relacionar esta pieza de imaginería con el hecho de que en otro texto Hobbes se llame a sí mismo como recién nacido 'pequeño gusano' (vermiculus)". HobBes, "T. Hobbes malmesburiensis vita", pp. lxxx-xcix, esp. p. lxxxv.

47 "The answer of mr Hobbes to Sr Will. Davenant's preface before Gondibert", en William Davenant, "The Author's Preface to His Much Honour'd Friend Mr Hobs", en Gondibert. An Heroick Poem, John Holden, London, 1651 (facsimile edition, Menston, London, 1970), pp. 7188, en p. 85: "For the Phrases of Poesy, as the airs of musick with often hearing become insipide, the Reader having no more sense of their force, then our Flesh is sensible of the bones that sustain it. As the sense we have of bodies, consisth in change and variety of impression, so also does the sense of language in the variety and changeable use of words. I mean not in the affectation of words newly brought home from travail, but in new (and with all significant) translation to our purposes, of those that be already received; and in far fetch't (but withal, apt, instructive and comly) similitudes". [Pues los versos de poesía, como las melodías de música, con el mucho oir se hacen insípidos, y el lector acaba teniendo tan poco sentido de su fuerza como de los huesos que sostienen nuestra carne. Como el sentido que tenemos de los cuerpos consiste en experimentar cambios y variedades de impresiones, así tambien en el lenguaje el sentido viene de la variedad y del uso cambiante de palabras. No me refiero a entender palabras recien incorporadas tras una trabajosa vida, sino a la nueva (y con gran trascendencia) traducción para nuestros propósitos de aquellas palabras 
símil (porrōthen $)^{48}$. Hay dos cosas que merecen atención. En primer lugar, a pesar de su crítica oficial a la metáfora, Hobbes desarrolla una visión muy sofisticada y matizada del buen funcionamiento de la metáfora. En segundo lugar, crea una atrevida metáfora relacionada con la ingestión y los intestinos: cuando censura las asociaciones dentro del Estado como subversivas y peligrosas para este, lo hace mediante la imagen de gusanos en los órganos internos del cuerpo humano; gusanos que parasitan y debilitan el cuerpo, comiéndoselo por dentro. Por lo que sabemos, este es un giro original y novedoso en la historia de la metáfora del cuerpo estatal; los conflictos subversivos han sido retratados a menudo en otros lugares como una guerra entre las diferentes partes del cuerpo - en el famoso discurso de Menenio Agripa en Tito Livio, por ejemplo, con los brazos y la boca protestando contra el vientre ${ }^{49}$ - . Hobbes, el declarado archienemigo de la metáfora, cuyas metáforas son sin duda muy meticulosamente diseñadas con el fin de transmitir el mensaje correcto, emplea así una metáfora de algo que es tragado y debilita el cuerpo desde dentro.

Hobbes insiste en este elemento de la imagen del cocodrilo o del Estado que devora y es derrotado por Cristo: el animal que subvierte la vida del animal anfitrión. Para hacer plausible esta interpretación, tendríamos que observar una indicación de que, para Hobbes, Jesús de Nazaret o el cristianismo en sí mismo este es un animal peligroso. ¿Podemos esperar tanto? Como cuestión de hecho, él dice algo similar:

Pues con los misterios de nuestra religión ocurre como con las saludables píldoras para los enfermos, que, tragadas enteras, tienen la virtud de curar, pero masticadas, son en su mayor parte devueltas sin efecto ${ }^{50}$.

que ya hemos recibido; y de [incorporar] similitudes que pueden ser poco verosímiles (pero aún así aptas, instructivas y elegantes)]. Cf., en un diferente contexto, HoBBES, Leviathan, xxix, 13, p. 257: "For the constitution of mans nature, is of it selfe subject to desire novelty". [Pues la constitución de la naturaleza del hombre es que el "yo" del sujeto desee la novedad].

${ }^{48}$ ARISTÓTELES, Retórica 1405a: eti de ou porrōthen dei, all' ek tōn syggenōn. Curiosamente, Quentin Skinner argumenta que Hobbes y Aristóteles concuerdan en este punto. SKINNER, Reason and Rhetoric in the Philosophy of Hobbes, p. 368.

${ }^{49}$ Tito Livio, Ab urbe condita, II:32. Cf. La visión general en "Organ, Organismus, Organisation, politischer Körper", en Otto BRUnNer, Werner CONZE \& Reinhart Koselleck (eds.), Geschichtliche Grundbegriffe, IV, Klett-Cotta, Stuttgart, 2004, pp. 519-622, esp. pp. 519-557; Susanne LÜdemann, "Körper, Organismus", en Ralf Konersmann (red.), Wörterbuch der philosophischen Metaphern, Wissenschaftliche Buchgesellschaft, Darmstadt, 2007, pp. 168-182.

50 "For it is with the mysteries of our Religion, as with wholsome pills for the sick, which swallowed whole, have the vertue to cure; but chewed, are for the most part cast up again without effect". HoBBes, Leviathan, xxxii, 3, p. 292. [HoBBES, Leviatán, p. 442]. 
Una vez más nos encontramos con una imagen literaria fascinante en torno a la ingestión - y esta vez Hobbes discute sobre la religión-. Su sarcasmo no puede ser más sencillo, no es de extrañar que muchos lo hayan visto como un pensador ateo obligado a ocultar su ateísmo detrás de la escritura esotérica. De acuerdo con su estricta distinción entre la teología y la filosofía, Hobbes dice que el pensamiento racional nunca puede satisfacerse con la religión, y utiliza la clase de ambigüedad que fue la mejor defensa y camuflaje para los pensadores heterodoxos en los inicios de la era moderna ${ }^{51}$.

El pasaje puede ser leído como una expresión de una visión piadosa y bastante anti-racionalista de los misterios de la fe: la razón no puede hacer justicia a estos misterios, por lo que es presuntuoso creer que la filosofía pudiese alcanzar conocimientos sobre el ser de Dios y de las últimas cosas. Sin embargo, la audaz imagen de Hobbes parece decir mucho más que eso. Las píldoras de la religión deben ser tragadas enteras, sin masticar, ya que una investigación más profunda - el masticar - implica que no funcionarán. Lo admitimos, afirma que las pastillas en cuestión son sanas, pero la imagen de los misterios cristianos como algo que debe ser tragado entero para que funcione parece una falta de respeto y escepticismo. Es evidente que se trata de un autor que cree que el misterio de la fe es una mera tontería. Estas palabras de aparente desprecio "vienen del corazón" 52. "Nos quedamos", como señala otro experto, "con la conclusión de que, si queremos aferrarnos a los misterios centrales del cristianismo, no tenemos otra alternativa que acercarnos a ellos con un espíritu de credulidad absoluta" ${ }^{\circ 3}$.

Lo decisivo aquí es que hemos descubierto una imagen, una imagen muy hobbesiana, en la que el cristianismo y Cristo han de ser "tragados". Esto será importante para nuestro argumento.

\section{LA DEBILIDAd DEL ESTAdo CRISTIANO}

Resumamos lo que hemos dicho hasta ahora. Curiosamente, Hobbes decide titular su opus magnum con el nombre de un monstruo bíblico ${ }^{54}$. El Leviatán puede interpretarse como un cocodrilo. Por otra parte, en la tradición europea existe una idea influyente del cocodrilo como una criatura enorme a la que otro animal, apa-

${ }^{51}$ Martin Mulsow, Die unanständige Gelehrtenrepublik. Wissen, Libertinage und Kommunikation in der frühen Neuzeit, J. B. Mezler, Stuttgart \& Weimar, pp. 91, 102, 106ss., 117.

52 J. C. A. GASKIn, "Introduction", en Thomas HobBes, The Elements of Law Natural and Politic, Oxford University Press, Oxford, 1984, pp. xi-xlii, esp. p. xli.

${ }^{53}$ SKINNER, Reason and Rhetoric in the Philosophy of Hobbes, p. 412.

${ }^{54}$ En este contexto no podemos desarrollar cualquier posibilidad de interpretación relacionado con otros animales: ballenas, pescado, dragones, serpientes. 
rentemente inofensivo, Cristo, vence dejándose devorar para luego derrotar al monstruoso animal desde dentro. Por otra parte, hemos visto otra imagen en la que los poderes societarios destruyen al Estado — poderes que son asimilables a los gusanos parásitos que debilitan y derrotan al animal anfitrión desde dentroY tenemos, por último, una imagen en la que la religión - la fe cristiana, en concreto - es representada como algo que uno se traga.

El Estado es por lo tanto un cocodrilo, y el cocodrilo puede ser derrotado por un ser vivo que se traga. Este ser vivo es Cristo. Las tres imágenes entran en una relación extraña. El Estado es un cocodrilo y el cocodrilo es asesinado por un ser en su vientre. Este ser es Cristo. Las tres imágenes se relacionan entre sí de una manera peculiar. Si el Estado es un cocodrilo, y si Cristo es peligroso para el cocodrilo, entonces el Cristianismo es peligroso para el Estado. El posible escepticismo de Hobbes vis a vis con las implicaciones políticas de la cristiandad no son en su propio contexto ni peculiares ni extrañas. Investigaciones recientes han demostrado que Hobbes estaba fascinado por las antiguas religiones paganas, y en particular, por sus funciones políticas ${ }^{55}$. Los Estados paganos podían mantener el orden entre sus súbditos de una manera muy diferente: podían exigir respeto al príncipe y a las leyes como una obligación religiosa.

Ciertamente, el cristianismo no es una religión de revolución política ${ }^{56}$. Pero en la historia del pensamiento político encontramos una vieja idea, que prevalece también en los pensadores que son denominados cristianos, en el sentido de que las religiones paganas eran políticamente superiores sobre la base de una sociedad en la que la obediencia al Estado era de suma importancia. Jean-Jacques Rousseau (1712-1778) más tarde celebraría las ideas de Hobbes y hablaría de "las divisiones intestinas que nunca han cesado de agitar a los pueblos cristianos" y diría que "lejos de unir los corazones de los ciudadanos al Estado, ella [la religión cristiana] los separa de este como de todas las cosas de la tierra"- para finalmente añadir: "No conozco nada más contrario al espíritu social" 57.

Las virtudes cristianas debilitan al Estado y hacen que sea incapaz de exigir y mantener el orden y la obediencia mediante la devoción. Este es un topos bien conocido en los inicios del pensamiento político moderno, particularmente

${ }^{55}$ Jeffrey Collins, The Allegiance of Thomas Hobbes, Oxford University Press, Oxford, 2005, pp. 11-57.

${ }_{56}^{56}$ Mateo 22:15-22, Romanos 13:4.

57 "[L]es divisiones intestines [sic] qui n'ont jamais cessé d'agiter les peuples chrétiens...loin d'attacher les cœurs des citoyens à l'Etat, elle les en détache comme de toutes les choses de la terre...Je ne connois rien de plus contraire à l'esprit social". Jean-Jacques Rousseau, Du contrat social ou principes du droit politique, Garnier, Paris, IV:8, pp. 329, 332. 
con respecto a la recepción de la herencia de la Antigüedad. Podemos estar perfectamente seguros al afirmar que Hobbes estaba bien versado en la tradición, en parte directamente por autores antiguos, como Diodoro, Tácito (56-117) y Polibio (200 a. e. c.-118 e. c.), pero probablemente también de forma indirecta a través de los escritores contemporáneos, como el filólogo holandés Gerardus Vossius (1577-1649). Estudios recientes han sostenido que Hobbes se inserta sistemáticamente a sí mismo en esa tradición ${ }^{58}$. El propósito siguiente es aportar una pieza preliminar y especulativa de evidencia circunstancial para apoyar la noción de que Hobbes era escéptico respecto al cristianismo por razones políticas. Por supuesto, esto no era algo que podría haber declarado explícitamente. Después de todo, en Inglaterra, la gente estaba siendo asesinada a causa de sus opiniones disidentes sobre cuestiones religiosas ${ }^{59}$.

Pero si leemos el título del cocodrilo de Hobbes como una alusión a la concepción sobre el cocodrilo ampliamente extendida, debido al libro de los animales más influyente de la tradición europea, tenemos que ver también la religión de Hobbes y su pensamiento político bajo una nueva luz. El cocodrilo es el Estado, y el cristianismo constituye una amenaza para el Estado. De una manera sutil e indirecta, Hobbes muestra su verdadera cara, su visión real del cristianismo, y su preferencia por un Estado que establece y mantiene la devoción religiosa para el soberano y el Estado mismo.

Se podría objetar que el cuento alegórico sobre el animal-Cristo que se sacrifica y derrota al cocodrilo no puede tener lugar en el universo moderno y científico de Hobbes. Pero si, como lo demuestran los estudios previos sobre Hobbes, Leviathan es el lugar donde Hobbes realmente rehabilita metáforas, imágenes y mitos como instrumentos de persuasión, entonces podemos sospechar que emplea imágenes de una tradición más antigua, imágenes que ya habían demostrado ser potentes en el caso de las pinturas de iglesias o en ilustraciones de libros. Además, en su autobiografía de 1672, él habla de pasada sobre cómo, cuando era joven, había estado fascinado con picta ignotis monstra videre locis ("monstruos pintados en lugares desconocidos", mapas, etc. $)^{60}$.

También podría objetarse que el Leviatán no había sido en ese momento identificado como un cocodrilo del Nilo - y que esto no sucedió hasta que el

${ }^{58}$ Ver más recientemente Collins, The Allegiance of Thomas Hobbes, pp. 44-54.

${ }^{59} 1697$ fue la última vez que una persona fue ejecutada por herejía en las islas británicas; ver John Coffey, Persecution and Toleration in Protestant England, 1558-1689, Longman, Harlow, 2000, p. 200.

${ }^{60}$ HobBes, “T. Hobbes malmesburiensis vita”, p. 1xxxii. 
Hierozoicon de Samuel Bochart (1599-1667) fue publicado en $1663^{61}$ - Pero esto no es correcto. Según Noel Malcolm, el primer estudioso que sugiere que el Leviatán era en realidad un cocodrilo debe haber sido Théodore de Bèze (15191605) en el siglo dieciséis. Curiosamente, Malcolm sostiene que "durante la primera mitad del siglo diecisiete, este punto de vista avanzó lentamente en los círculos protestantes (las anotaciones bíblicas de la Asamblea de Westminster, por ejemplo, glosaron al "Leviatán" como "una ballena, o un remolino, o para algunos, como un cocodrilo)" ${ }^{\prime \prime 2}$.

Hay, pues, buenas razones para suponer que Hobbes estaba familiarizado con la interpretación del Leviatán como un cocodrilo; lo cual es, tal vez, incluso una buena razón para otorgar al cocodrilo un estatus muy especial en la comprensión del Leviatán en ese momento.

Se podría objetar que es demasiado audaz creer que la alegoría del cocodrilo tenía alguna importancia en el contexto de Hobbes. Pero esto sería igualmente equivocado: el Physiologus fue enormemente influyente en la cultura occidental hasta los primeros tiempos modernos. Si, como podemos sospechar con razón, Hobbes estaba familiarizado con la idea de que el Leviatán era en realidad un cocodrilo, entonces también debemos relacionar su Leviatán con la alegoría del cocodrilo.

Hobbes mismo mencionó el primer eslabón de la cadena, la obra de Aristóteles sobre los animales. Y sabemos que había estudiado a fondo a Diodoro de Sicilia, en cuya obra se encuentra la observación del pequeño animal que mata al cocodrilo desde dentro. Sus estudios sobre Diodoro probablemente habían tenido lugar principalmente cuando Hobbes era todavía un hombre joven, pero son abundantes sus citas del historiador siciliano casi dos décadas después de Leviathan. De hecho, Hobbes cita el libro de Diodoro sobre Egipto, la misma obra donde Diodoro habla del cocodrilo y el ichneumōn ${ }^{63}$. De ese modo, conoce bien las fuentes antiguas de la historia de cocodrilo. El papel del Physiologus en la tradición europea, que se extiende hasta bien entrado el siglo diecisiete, no necesita ser mencionado nuevamente. La alegoría del cocodrilo estaba ya mediada por innumerables obras: el enydros o el ichneumōn y el cocodrilo eran básicos en los bestiarios medievales ${ }^{64}$.

${ }^{61}$ Bernström, "Krokodil och ichneumon”, p. 207.

${ }^{62}$ MALCOLM, "The Name and Nature of Leviathan", p. 29.

${ }^{63}$ Thomas HoBbes, Behemoth or the Long Parliament, University of Chicago Press, Chicago, 1990, pp. 91ss.

${ }^{64}$ Aberdeen University Library MS 24 f69r: "hic idrus [enydros] satis est inimicus cocodrillo". 
La "nueva" imagen del Leviatán como un cocodrilo que surge en los siglos dieciséis y diecisiete debía ser bien conocida por Hobbes, que era un gran conocedor de las Sagradas Escrituras, y lo mismo debía ser cierto sobre la "vieja" alegoría cristiana en la que Cristo vence al cocodrilo. Si este es el caso, entonces podemos entender la imagen del Estado de Hobbes como el Leviatán al modo de una señal sutil. Hobbes está - de esto podemos estar seguros - siempre a favor del Estado. Pero esto significa que él apoya, en este caso, no a Cristo, sino al cocodrilo. Esto, por supuesto, no implica que Hobbes apoye al diablo en el sentido de que es un satanista o un ateo en el sentido estricto. Por otra parte, esta interpretación no tiene que ver con sus puntos de vista teológicos, sino con su punto de vista eclesiológico y político. Sin embargo, para un pensador que no solo es escéptico sobre las afirmaciones teológicas del cristianismo, sino que también está convencido de que la religión de Cristo es políticamente inferior y potencialmente destructiva, el único camino a seguir es hablar a través de un portavoz alegórico. La estabilidad del Estado exige devoción y reverencia, de acuerdo precisamente con los modelos paganos; por eso, para Hobbes, los Estados necesitan cambiar. Los Estados deben ser menos cristianos, más paganos.

Traducción de Pedro Mendoza Lamuño 